\title{
Development of a virtual classroom to teach biochemistry
}

\author{
Rodrigues, R.S.; Castro, M.S.; Fontes, W.
}

Laboratório de Bioquímica e Quimica de Proteinas - Departamento de Biologia Celular - Universidade de Brasília

Knowing the difficulties to teach some biochemistry concepts because of their dynamic and spatial characteristics, computers have been adopted to help in these visualizations. Pictures, three dimensional structures and animations were built and used to display in classes and distributed to students. Behind these specific illustrations, an informatics environment has been developed to support biochemistry teaching. Based in free software, it fits in a single CD that works independent of any software installed on the computer, even the operating system, and is compatible with most hardware configurations.

This technique is called live-CD. It is based on Linux architecture, which is not only free software but also more flexible to be configured. After some tests with Linux distributions, Slackware has been chosen because of its easy manipulation and because it makes the best use of the hardware allowing to be installed in old or limited equipments. It has been configured to make the best optimization of the computer and have all software needed for most biochemistry classrooms.

It was installed: an Internet browser compatible with a 3D molecule visualization plug-in, text editor, presentation editor, picture editor and some didactic material specific for biochemistry. The interface was configured for people with no experience in the Linux environment.

The system can also work in an intranet, where a computer would be operated by the teacher and it would have some special control configurations as: web site access control, power control of the others machines and even an option that would bring the desktop of other machine to the teacherś what allows him to make a straight orientation for a student from his screen.

This new system, which is a common platform for other didactic material projects, broadens the usage of animations and teach sites during the class or for individual studies. The students can improve their experience in learning biochemistry without having to buy expensive software.

This system will be distributed over the Internet for the teachers and students interested in trying, learning, using and helping the development of the new system.

Support: FUB/UnB 